\title{
CORRECTION
}

\section{Correction to: Novel monitoring method for belt wear state based on machine vision and image processing under grinding parameter variation}

\author{
Nina Wang ${ }^{1}$ - Guangpeng Zhang ${ }^{1} \cdot$ Lijuan Ren $^{1} \cdot$ Wanjing Pang ${ }^{1} \cdot$ Yongchang $\mathrm{Li}^{1}$
}

Published online: 2 February 2022

○ The Author(s), under exclusive licence to Springer-Verlag London Ltd., part of Springer Nature 2022

\section{Correction to: The International Journal of Advanced Manufacturing Technology https://doi.org/10.1007/s00170-021-08393-5}

The original article contained a mistake.

Figures 1 and 2 do not displayed correctly in the published paper. Correct Figs. 1 and 2 are shown here.

Fig. 1 The framework of belt condition monitoring

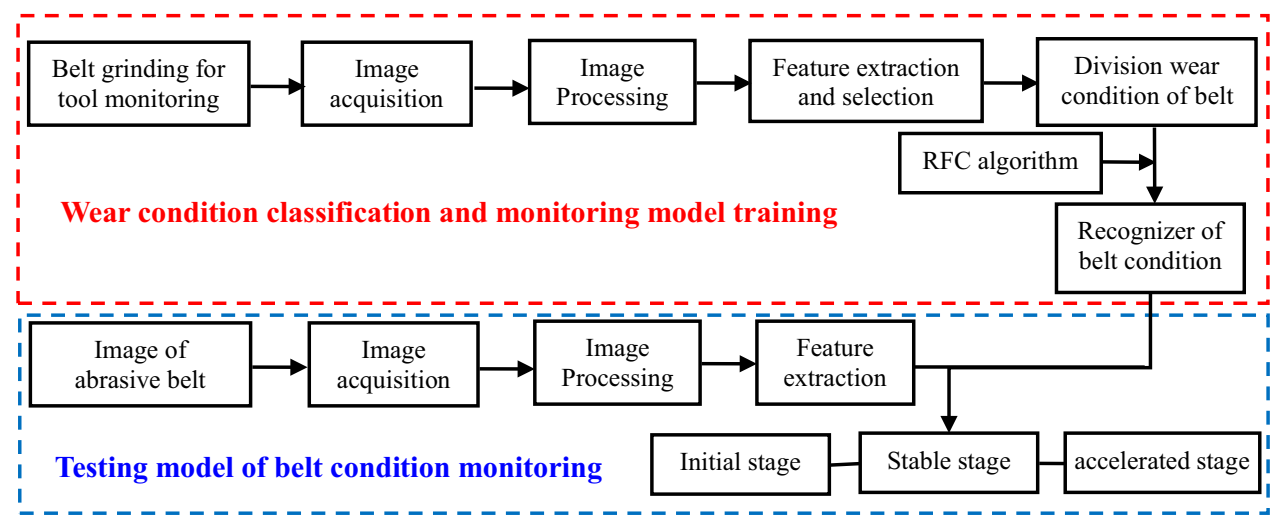

The original article can be found online at https://doi.org/10.1007/ s00170-021-08393-5.

Guangpeng Zhang

gpzhang@xaut.edu.cn

1 School of Mechanical and Precision Instrument Engineering,

Xi'an University of Technology, Xi' an 710048, China 
Fig. 2 Experimental setup

Grinding equipment

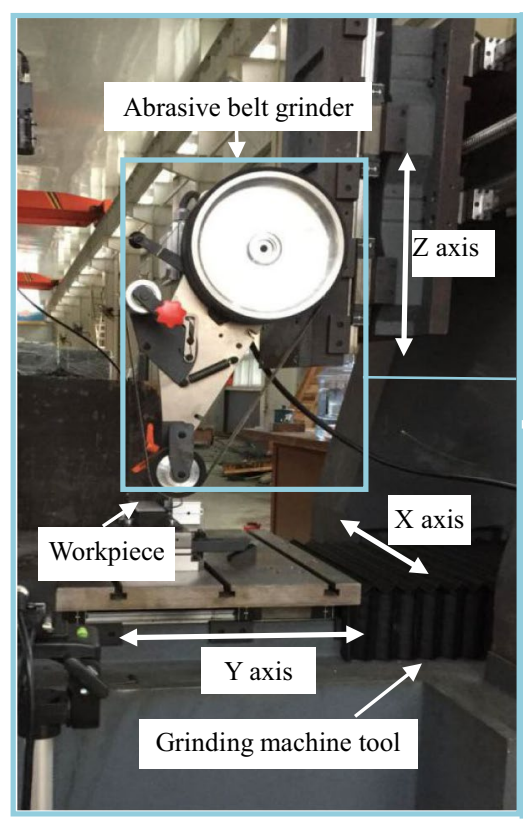

Measuring equipment

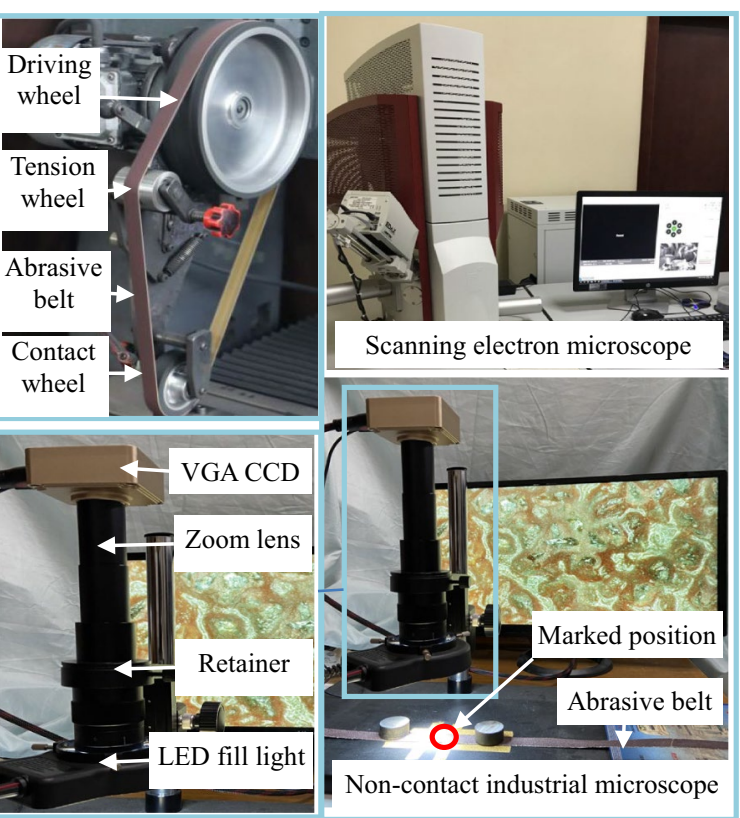

The original article has been corrected.

Publisher's Note Springer Nature remains neutral with regard to jurisdictional claims in published maps and institutional affiliations. 